\title{
Apontamentos teóricos sobre Literatura de Viagens
}

\author{
Paula Cristina Ribeiro da Rocha \\ de Morais Cunha
}


CARACOL 3 / DOSSIÊ

PALAVRAS-CHAVE: Literatura
de viagens; Gênero híbrido;
Literatura e realidade;
Imagologia; Alteridade.
KEYworDs: Travel literature;
Hybrid genre; Literature and
reality; Imagology; Otherness.
Resumo: A literatura de viagens é um gênero que agrega tipologias textuais diversificadas, o que faz dela um gênero de fronteira, também pela circunstância de problematizar a separação epistemológica entre ficção e realidade. Caracterizar teoricamente o gênero viático é pensar na natureza e complexidade do fenômeno literário que, utilizando como intermediário a linguagem, coloca sempre a questão da capacidade mimética da linguagem, isto é, a capacidade da linguagem de representar a realidade. Por se tratar de um gênero em que, frequentemente, o narrador-viajante aborda uma cultura estrangeira, a literatura de viagens é rica em imagens literárias do outro civilizacional, tornando-se, por isso, um terreno fértil para os estudos imagológicos, que analisam a forma como dada cultura percepciona a outra e como as ordens discursivas servem à perpetuação de estereótipos.

ABSTRACT: Travel literature is a genre that combines different textual typologies and discusses the epistemological separation between fiction and reality. These aspects make it a kind of border genre. To characterize travel literature is to think about the nature and complexity of the literary phenomenon which uses language as an intermediary between literature and reality and questions the capacity language has to represent reality. Because it is a genre in which the 
Apontamentos teóricos Sobre Literatura de Viagens

Paula Cristina Ribeiro da Rocha de Morais Cunha

traveler, who is also the narrator, approaches a foreign culture, travel literature abounds with literary images

of the other. Thus it is a fertile ground for studies that

analyze the way a culture sees the other and the way

discursive speech perpetuates stereotypes. 
CARACOL 3 / DOSSIÊ

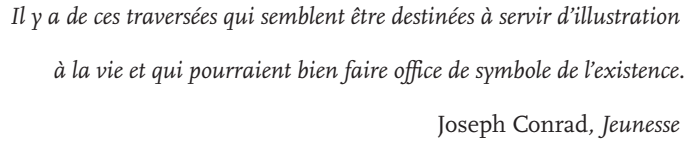

PARA ABORDAR teORICAMENTE a literatura de viagens, convém ter em conta que se trata de um gênero de fronteira que se foi consolidando em torno de textos provenientes de matrizes e de contextos históricos diversos. Afirma-se, na Europa, entre os séculos XV e XVI, em consequência das viagens marítimas ao novo mundo, e assume a forma de cartas, diários, registros de bordo, relatos de naufrágio, textos de natureza plural que à viagem foram buscar formas, motivos e temas.

A compulsação de textos mais recentes deixa perceber que um dos traços caracterizadores da literatura de viagens contemporânea se relaciona com o cunho autobiográfico que o narrador-viajante empresta ao relato, na medida em que a exibição da sua experiência vivencial e subjetiva imprime um caráter particular ao récit. Por conseguinte, o eu que conduz a narrativa assume um papel de primeiro plano, já que a sua função não se reduz a de informar, mas é a própria experiência que motiva o ato da escrita. Não é, com efeito, tanto a paisagem que o narrador-viajante quer dar a ver, antes a sua relação com o espaço e cultura, estrangeira ou de pertença, num determinado período de tempo. Visto que estes discursos remetem a uma dimensão intimista, o posicionamento privilegiado do eu viajante, que, de uma maneira geral, coincide com o eu que relata a viagem, determina o tom, por vezes, irregular, dos relatos - ou plural, em razão dos diferentes registros utilizados e dos tempos diferentes que correspondem à dupla experiência da viagem e da escrita -, pois o narrador, se molda o seu discurso às especificidades do gênero, tem que contar com a 
Apontamentos teóricos Sobre Literatura de Viagens

Paula Cristina Ribeiro da Rocha de Morais Cunha

memória, que disporá a matéria narrativa numa sequência organizada, tendencialmente linear, porquanto segue a cronologia dos acontecimentos.

Neste sentido, é enquanto apreensão pessoal e subjetiva que os relatos de viagem são apresentados à instância de leitura, que recebe essas impressões da realidade como captação do olhar do viajante. Determinar o material que poderá constituir-se como matéria narrativa é fundamental, inclusive em termos imagológicos, pelo fato de as escolhas efetuadas serem suscetíveis de revelar, por um lado, a mitologia do narrador-viajante, e, por outro, o imaginário do seu tempo. De fato, muitas das imagens que circulam na literatura de determinada época dão conta da maneira como uma dada sociedade vê a outra. A auto-percepção de uma cultura revela, na verdade, o seu sistema de representações, porquanto a forma como uma comunidade percepciona outra, estrangeira, mostra os esquemas interpretativos em funcionamento na cultura de pertença, através das suas projecções, crenças, preconceitos.

Também o processo de construção do sujeito que narra, e que se distancia no tempo do autor real - para além da circunstância de a linguagem funcionar já como filtro e de o sujeito ser, sobretudo, uma figura de linguagem - revela-se complexo no gênero viático. Este sujeito que parece mostrar-se, na verdade, esconde-se por detrás de um discurso autobiográfico de primeira pessoa, na medida em que é difícil determinar o que releva de uma experiência real, original, e o que é construído para produzir, literariamente, uma imagem ou representação cultural. Se a estratégia se justifica, em consequência das especificidades do gênero, que, enquanto domínio de uma literatura pessoal, se alimenta desse jogo de credibilização da experiência do autor, a modernidade ensinou que a construção da subjetividade, mediada pela linguagem, é um jogo de espelhos e a literatura, um campo propício a ficções e fingimentos. Friedrich Wolfzettel, no artigo "Relato de viaje y estructura mítica", considera que "viajar siempre es 
CARACOL 3 / DOSSIÊ

enter a dark crystal, ser iniciado en los aspectos escondidos del mundo exterior; viajar siempre es establecer una conexión entre estos aspectos exteriores y el yo secreto." (Tobar, 2005, Io). Esta percepção individual do narrador-viajante materializa-se imageticamente no texto e interessa, sobremaneira, à Imagologia, disciplina para a qual os textos de viagem se constituem como material relevante na análise da imagem enquanto "expressão literária" (Pageaux, 2004) de uma ordem cultural e ideológica dominante.

Sendo a prática intertextual constitutiva do exercício literário, a circunstância de os relatos de viagem reivindicarem uma plataforma de referencialidade parece torná-los particulares, revelando assim o caráter de construção destes discursos. Como saber o que deriva da observação do narrador-viajante e o que faz eco de suas leituras, apontando, por conseguinte, para a tradição literária? O que é oferecido ao leitor não é somente a originalidade do relato naquilo que poderia traduzir de um olhar pessoal sobre uma dada cultura, e que conformaria a realidade apreendida por um indivíduo num dado período, mas também uma síntese de referências que se atualizam no relato próprio e trazem ressonância de textos anteriores, explícita ou tacitamente:

Con la excepción de los libros fundacionales sobre las grandes rutas viajeras, los relatos de viaje se nutren tanto de la experiencia real del viajero como de la escritura de relatos anteriores. El relato personal de un viaje entreverá un «yo he visto» con un «yo he leído» de una forma inextricable que, en muchas ocasiones, hace muy difícil al lector el poder separar lo que ha sido experiencia directa del escritor y ecos de las lecturas de otros relatos de viajes anteriores, bien porque éstos han sido tomados con "guía" práctica para el nuevo viajero bien porque la memoria de éste no puede borrar las huellas que le han dejado los textos leídos antes de la redacción del suyo proprio.

(Tobar, 2005, 132). 
Apontamentos teóricos sobre Literatura de Viagens

Paula Cristina Ribeiro da Rocha de Morais Cunha

Em Introducción a la literatura comparada (2002), Domenico Nucera reflete acerca da relação entre a viagem e a escrita, no capítulo "Los viajes y la literatura”. O póprio título traduz a flutuação intrínseca ao gênero, uma vez que deixa perceber a relação de contiguidade entre dois domínios: o da realidade, por um lado, e o da literatura, por outro. Com efeito, este tipo de discurso remete ao campo de exterioridade, uma vez que inscreve o lugar de um sujeito (ou de vários) que empreendeu uma viagem (ou que a imaginou, podendo socorrer-se de estratégias de verossimilhança). Remete, ainda, para o campo social, pois o plural “viajes” aponta um domínio que, enquanto prática cultural, é passível de ser historicizado e, enquanto prática discursiva, alvo de reflexão e sistematização teórica.

Nucera aborda a problemática da autonomização de um gênero que tem, desde a gênese, o cunho da pluralidade, pois acolhe uma grande diversidade de tipologias: "Entonces, ¿la literatura de viajes ha llegado a ser un género literario autónomo y de éxito?" (2002, 24I). Considerar os textos que resultaram das primeiras impressões de viagem dos navegadores ao Novo Mundo, os quais tinham uma natureza, fundamentalmente, documental, e incluí-los no mesmo rol dos textos utópicos setecentistas, como Robinson Crusoe, ou dos relatos contemporâneos de Bruce Chatwin ou de Paul Theroux é lançar um olhar abrangente à evolução do gênero e considerar o alargamento do seu âmbito. A determinação dos critérios para definir o gênero tem de ponderar quais os textos que, para além de uma dimensão pragmática, possuem valor estético e poderão constituir-se como candidatos a obras literárias. Como recorda Roland Barthes ${ }^{\mathrm{I}}$ (I987), não é possível operar com o método indutivo de leitura

I Em A aventura semiológica, Roland Barthes parte da seguinte indagação teórico-literária: “Que dizer então da análise narrativa, colocada perante milhões de narrativas? Está, forçosamente, condenada a um processo dedutivo; é obrigada a conceber, em primeiro lugar, um modelo hipotético de descrição

158 
e análise de todas as narrativas existentes. O método dedutivo, por ser um procedimento descritivo e teórico, permite dar conta dos elementos estruturais que podem configurar um modelo textual num dado momento histórico. Mas se a análise estrutural permite estabelecer um "modelo geral" capaz de abarcar todas as narrativas de um determinado gênero, é, evidentemente, a partir de textos concretos e da maneira como eles funcionam no sistema semiológico literário que é possível determinar os seus traços distintivos. Daí a indagação pertinente de Nucera:

[...] ¿cómo hay que clasificarlos? ¿No será tal vez oportuno articular esa notable masa de textos en distintos subgéneros? Y las guías de viaje, ¿entran o no en el coto general? ¿O son paraliteratura, literatura popular, un subgénero distinto y especial, o qué cosa? (2002, 24I).

A partir do momento em que pretende constituir-se como gênero autônomo, a literatura de viagens deixa de ser um "intermediário literário", embora não perca a natureza de gênero de fronteira. Philippe Antoine, em Les récits de voyage de Chateaubriand (1997), enuncia o caráter ambivalente dos textos de viagem: o seu poder referencial, isto é, a pretensa transparência de discursos que deixariam ver a realidade, por um lado, e o seu estatuto literário, produto de um trabalho sobre a linguagem, por outro:

(...) s'il n'ya a pas d'incompatibilité absolue entre la littérarité du Voyage et son aptitude à rendre compte d'un réel préexistant, il y a tout de même un conflit, et une contradiction à résoudre: vouloir dire les choses comme elles sont revient à admettre l'hypothèse

(a que os linguistas chamam uma "teoria"), e depois descer, pouco a pouco, a partir desse modelo, até às espécies que, simultaneamente, dele participam e dele se afastam [...]” (Barthes, I987, 96). 
Apontamentos teóricos sobre Literatura de Viagens

Paula Cristina Ribeiro da Rocha de Morais Cunha

d'une écriture transparente, et à sacrifier la visée poétique du récit; faire oeuvre de création revient peu ou prou à trahir le référent que l'on prétendait fidèlement servir. Posé dans ces termes, le questionnement relève de l'aporie. Plus prudemment, et de manière plus réaliste, il vaut mieux se demander quels procédés littéraires sont à l'oeuvre dans le texte, qui nous font par endroit oublier sa littérarité et voir, inversement, s'il n'arrive pas que le réel soit enseveli sous les mots qu'il disparaisse. (Antoine, I997, 28-29)

Reivindicar para as narrativas de viagem um efeito de transparência equivaleria a menoscabá-las como produto de investimento estético e, do mesmo modo, sublinhar o trabalho literário de textos que querem mostrar o real pareceria comprometê-los na sua dimensão referencial. Afinal, toda narrativa se oferece, antes de mais, como elaboração discursiva.

Essa mesma circunstância de incorporar textos de tipologias diversificadas dificulta a autonomização de um gênero considerado "omnívoro" (Nucera, 2002, 242). Philippe Antoine parece resolver bem a questão, ao considerar estratos ou camadas na organização discursiva destes textos:

Nous ferons ici l'hypothèse suivante, d'un récit de voyage qui serait défini par l'alternance non hiérarchisée de séquences textuelles, par la présence d'un voyageur (narrateur et personnage) qui est le garant de la cohésion du texte, et par la récurrence de thèmes liés à l'espace aussi bien qu’au temps. (Antoine, I997, 26).

Jean Richard fala de "un genre multiforme", ainda que se circunscreva à literatura escrita no mundo ocidental entre os séculos XIII e XVI:

La difficulté de l'étude de ce type d'ouvrages tient à son extrême variété. C'est un genre multiforme, puisqu'il va des guides destinés aux voyageurs et surtout aux pélerins, aux

160 
CARACOL 3 / DOSSIÊ

marchands aussi, en passant par les lettres et relations des ambassadeurs et des missionnaires, les récits d'expéditions lointaines, ceux des aventuriers, jusqu'à des oeuvres de caractère nettement géographique. L'objet n'en est pas identique, les lecteurs ne sont pas les mêmes. Les caractéristiques de la rédaction varient en fonction de ces impératifs. [...] C'est donc la variété des textes susceptibles de rentrer dans cette littérature qui fait la difficulté d'une typologie. (Richard, I98I, 8-9).

Para se chegar a uma caracterização da literatura de viagens, é conveniente partir do conceito de viagem. Viajar, numa acepção primeira, implica deslocação, movimento físico. Neste sentido, por narrativa de viagem teria de se entender todo o texto que remetesse para uma jornada, com marcadores temporais e espaciais definidos. Para além disso, é consensual que os textos de viagem são recebidos pelo leitorado como resultado de uma experiência real. No entanto, muitas obras que podem considerar-se literatura de viagens, a exemplo de Robinson Crusoe, são narrativas ficcionais. E um texto como Viagem à Itália mentiria se fosse entendido como documento que caucionasse a experiência do autor, uma vez que Goethe nem chegou a terminar a viagem. É evidente que, em literatura, os textos não são verdadeiros nem falsos, na sua dimensão verbal, na medida em que funcionam dentro de um sistema, o literário, que detém as suas próprias regras, avessas a critérios de verdade ou de falsidade. No entanto, a natureza referencial das narrativas de viagem satura-as de elementos indexicais e deíticos. Só que a viagem presta-se à metaforização; afinal, ela se confunde com a própria vida na sua transitividade:

Qu'est-ce qui n'est pas un voyage? Pour peu qu'on donne une extension figurée à ce terme - et on n'a jamais pu se retenir de le faire - le voyage coïncide avec la vie, ni plus ni moins: celle-ci est-elle autre chose qu'un passage de la naissance à la mort ? Le déplacement dans l'espace est le signe premier, le plus facile, du changement; or qui 
Apontamentos teóricos sobre Literatura de Viagens

Paula Cristina Ribeiro da Rocha de Morais Cunha

dit vie dit changement. Le récit aussi se nourrit du changement. Le voyage dans l'espace symbolise le passage du temps, le déplacement physique le fait pour la mutation intérieure; tout est voyage, mais c'est donc un tout sans identité. Le voyage transcende toutes les catégories, jusqu'à et y compris celle du changement, du même et de l'autre, puisque dès la plus haute Antiquité on met côte à côte voyages de découverte, exploration de l'inconnu, et voyages de retour, réappropriation du familier: les Argonautes sont grands voyageurs, mais Ulysse en est un aussi. (Todorov, I99I, 94).

A acepção metafórica ou alegórica de viagem conduz à concepção criadora da linguagem. Neste sentido, escrever é, também, viajar. Será a tematização da viagem um elemento que permite caracterizar o gênero viático? Se assim for, obras como Ulisses, de James Joyce, ou a Divina comédia, de Dante, terão que ser consideradas textos de viagem.

A edição de pendor didático Qu'est-ce que la littérature de voyage? (200I), de Odile Gannier, elege, precisamente, como critério principal para o estabelecimento do gênero a relação do sujeito-viajante com a realidade. Como se sabe, as questões da referencialidade em literatura ganharam contornos particulares em torno das discussões teórico-literárias da estética realista. Não obstante, se a objetividade parece conformar-se com textos desta natureza, textos que têm na descrição da realidade exterior paisagens naturais e humanas, uma edificação discursiva importante, a verdade é que o fato de se tratar, fundamentalmente, de registos de primeira pessoa faz deles produtos da subjetividade do autor. Do mesmo modo, é problemático usar as categorias real vs ficcional para pensar a literatura viática - quer porque existem relatos de viagens imaginárias ou fictícias, quer porque a circunstância de se falar de uma realidade outra, a partir da perspectiva do mesmo, relativiza estes binômios. Como refere ainda Odile Gannier: "les lecteurs ou les auditeurs peuvent aussi décider de la réalité du genre : ils peuvent le croire conforme au réel, ou non, indépendamment de l'adéquation 
effective" (200I, 7). Esta preocupação com o leitorado vai determinar, em grande medida, a legibilidade destes textos, que se esforçam por ir ao encontro das expectativas do leitor e das suas referências culturais e ideológicas, ancoradouros importantes na abordagem da cultura estrangeira.

A apropriação da temática da viagem - e respectiva atualização discursiva - para o conhecimento realiza-se em duas vertentes: como gênero literário autônomo e como fonte de documentação histórica. Importa, ainda, distinguir viagem na literatura e literatura de viagens como gênero com especificidades próprias. A viagem é o tema aglutinador de um conjunto de textos que se autonomizam em torno dessa prática. Tal confluência temática não pode, no entanto, confundir-se com a presença da viagem na literatura: não só porque o tema da viagem não é exclusivo da literatura de viagens, mas também porque são as características genológicas dominantes que justificam a categorização de determinado texto. As "categorias semiológicas, históricas, de edição e de recepção" (Cristóvão, 2002, I6) que modelam o gênero não podem, pois, confundir-se com as de outras tipologias, mesmo quando o tema da viagem figura enquanto tema. Por outro lado, entender a viagem na literatura estritamente como movimentação no espaço parece empobrecedor, uma vez que tal acepção seria igualmente pertinente para designar campanhas militares, por exemplo. Então, qual a especificidade da viagem para a literatura de viagens? James M. Buzard questiona o conceito de viagem, sintomaticamente, pela negativa - What isn't travel? -, para dar conta da saturação do signo, para sugerir precisamente esta ideia de plurissignificação do conceito, procurando critérios que estabeleçam uma base conceitual para a literatura de viagens:

(...) we cannot rest easy with even a form of Travel Studies that ignores all kinds of passages through the world, focuses only on the self-motivated "journey of discovery" 
Apontamentos teóricos sobre Literatura de Viagens

Paula Cristina Ribeiro da Rocha de Morais Cunha

or on the avocational reflective tour and does not even provide a rationale for doing so

(Buzard, 2005, 56).

Perseguindo essa amplitude do termo, conclui o mesmo estudioso que a viagem depende de um comportamento humano intencional ${ }^{2}$ e temporário, pois implica regresso, sendo a ideia de périplo fundamental desde a Odisseia cujo herói, Ulisses, regressa a Ítaca. No entanto, estes critérios podem, igualmente, ser questionados: será possível delimitar a duração e a distância de uma "movimentação” ou “deslocamento” para que se considere, legitimamente, viagem?

How do we know when someone is travelling? should be taken as asking, What is the historical landscape of material and discursive conditions in which something recognised as "travel" emerges? How do particular societies configure the boundary between movement and travel? Which do they regard as real travel - the journey across considerable distance that seemed to require no great mental "displacement", or the tiny step outside the customary path that ushered one into unsuspected realms of otherness? Do they make such a distinction, and, if not, why not? What counts as difference? What does it mean to go "someplace else" - and how does this meaning change? Where are a society's boundaries between one "place" and another? (Buzard, 2005, 59-60)

Quer se considere a tematização ${ }^{3}$ da viagem, quer se considerem os relatos que assentam na experiência efetiva da viagem, os textos que se produzem em torno deste deslocamento, real ou imaginário, respondem, frequentemente, à necessidade de pensar a prática da viagem enquanto gesto introspectivo

2 De acordo com Buzard, “(...) mere locomotion or the physical covering of distance [is] not travel. (...) Travel [is] purposive, not instinctual” (Buzard, 2005, 55).

3 Textos clássicos em que a viagem é tematizada: Odisseia, Divina comédia, Dom Quixote, Os lusíadas, As viagens de Gulliver.

164 
e processo de auto-conhecimento. A ânsia de conhecimento, a necessidade de experienciar novos contextos, de se transcender, impulsiona o ser humano para a viagem. Qual Sísifo, o ser humano aspira à superação das limitações existenciais. A escrita é, também, uma forma de viagem e, do mesmo modo, a leitura que "imite, dans une certaine mesure, le contenu du récit: c'est un voyage dans le livre" (Todorov, I99I, I05-I06). Desde as viagens de aventura às viagens de índole espiritual, como as peregrinações, o conceito é semanticamente rico: procura da verdade, fuga de si mesmo, encontro com o outro, aceitação da morte.

Já na Idade Média, a apetência por textos que ofereciam a possibilidade de contatar com outras culturas atesta o potencial de escritos que, radicados na realidade, não anulavam o exotismo: "Mais sans réellement entrer dans la littérature de voyages, ces oeuvres attestent l'attrait qu'exerce sur le public médiéval le dépaysement et les aventures que réservent les pays exotiques supposés riches en 'merveilles'”. (Richard, I98I, 9). Nascida sob os auspícios da Expansão, a literatura de viagens encontra-se na transição de uma época obscurantista para uma era de desocultação do mundo e das mentalidades, com o espírito humano a ser desafiado pelas novas descobertas. Perante novas terras e povos até então desconhecidos, o espírito de cruzada dos viajantes fê-los reconhecer nos novos territórios coordenadas bíblicas. Essas terras impunham, no entanto, um reordenamento cosmológico que não se compatibilizava com a cosmologia das Escrituras. Uma concepção diferente do universo estabelecia-se e com ela a exigência de novos instrumentos para o interpretar, isto é, um arcabouço intelectual apto a assimilar os dados novos. E as narrativas de viagem constituíam o suporte informativo desse novo mundo. Por força das circunstâncias, foram os navegantes e exploradores os autores desses primeiros textos.

O espírito das Luzes valorizava nos textos de viagem a reflexão filosófica que favoreciam. Pense-se nos desdobramentos que terão as ideias rousseaunianas 
Apontamentos teóricos sobre Literatura de Viagens

Paula Cristina Ribeiro da Rocha de Morais Cunha

acerca do bom selvagem e do primitivismo, defensoras da inocência dos povos indígenas cuja natureza seria incorrupta por estar afastada da "civilização". Para além disso, no século XVIII, estabeleceram-se alguns dos elementos estruturais da literatura de viagens: "In the eighteenth century, that witnessed the peak of scientific travel writing, and in which the basic form of the genre as an accepted literary form was established travel writing was tremendously en vogue" (ShulzForberg, 2005, 26).

No século XIX, o interesse pelos textos de viagem, por aquilo que representavam enquanto promessa de aventura, exotismo e dépaysement, conheceu novos contornos. A expansão dos impérios francês e britânico aproximou os artistas da realidade do Próximo e Médio Oriente. Os quadros de Delacroix e de Ingres, por exemplo, ilustram a tendência oitocentista para representar paisagens e costumes orientais, revelando o fascínio que exerciam sobre a cultura europeia.

Segundo Gérard Cogez, Diderot já reconhecia em Description d'un voyage autour du monde (I77I), de Bougainville, qualidades literárias4. No entanto, o estabelecimento do gênero com foros próprios teria que esperar pelo século XIX: "C'est au XIXe siècle que le récit de voyage trouvera une place entière à l'intérieur du champ littéraire" (Cogez, 2004, I4). Chateaubriand concederia os pergaminhos ao gênero viático: primeiro, com Atala, obra que disfarça, na verdade, uma viagem efetiva do autor à América do Norte, em I79I; depois, com Itinéraire de Paris à Jerusalém, narrativa datada de i8Ir. Também Sentimental Journey, de Laurence Stern, é considerado um texto fundador para a literatura de viagens. Autores ilustres como Gérard de Nerval, Victor Hugo, Astolphe de

4 Cogez refere-se à opinião de Diderot a propósito do texto setecentista: "Il s'agit, peut-être, de la première ébauche d'un changement de statut du récit de voyage: il se rapproche incontestablement, grâce à l'auteur de Jacques le fataliste, de l'institution littéraire proprement dite, même s'il n'y figure encore qu'en invité" (2004,13).

166 
Custine, Mérimée, Théophile Gautier gravitaram pela literatura de viagens que, nesta época, conhecia já uma vasta produção. Já as obras de ficção científica de Jules Verne, por exemplo, com travejamentos semelhantes aos das narrativas de viagem reais, distinguem-se delas pela funcionalidade da viagem, uma vez que, segundo Fernando Cristóvão, "não participam da hybris renascentista e moderna da literatura de viagens" $(2002,52)$. Embora se reconheçam qualidades literárias em muitos textos que se firmaram na experiência real da viagem, uma certa marginalidade continua, no entanto, a ensombrar a literatura de viagens, considerada para-literatura, um sub-gênero dentro do sistema literário.

No século XIX, o fenômeno do turismo modificou, radicalmente, a relação do indivíduo com a viagem, pela possibilidade que oferecia ao viajante de percorrer vastos espaços com grande economia de tempo. Esta indústria, no entanto, se trazia claras vantagens na preparação e duração da viagem, inclusive, com o surgimento de agências, retirava, de algum modo, o carácter imprevisível e romântico da empresa, ao mesmo tempo que produzia uma nova categoria social, o turista, cujo principal interesse parecia ser a recreação, contrariamente ao viajante, cuja postura em relação à viagem evoca a aura do nômade, que viaja para se outrar.

No século XX, os Estudos Culturais e Pós-Coloniais denunciavam o imperialismo e a perspectiva centralizadora que percorria as narrativas de viagem ocidentais, veículo privilegiado da cultura do velho continente e instrumento de consolidação da ideologia europeia. No decurso deste século, o modo de viajar e a prática da viagem sofreram alterações significativas. Com efeito, a própria relação do viajante com a realidade estrangeira e com o outro civilizacional, visto então como sujeito dotado de sensibilidade própria, modificou-se. Muitas narrativas de viagem conheceram grande notoriedade literária, o que conduziu ao redimensionamento do próprio gênero: 
Apontamentos teóricos sobre Literatura de Viagens

Paula Cristina Ribeiro da Rocha de Morais Cunha

En fait, à l'aube du XXe siècle, il ne fait plus guère de doute qu'un nombre respectable de récits de voyage appartiennent au domaine littéraire, en ce sens qu'il manifestent un incontestable souci de style de composition. Le problème qui demeure est celui du genre lui-même, dans la mesure où les conditions et la conception même du voyage se sont considérablement modifiées en quelques décennies: évolution des moyens de transport, développement considérable des déplacements, qui saturent la quasi-totalité de la planète, remplacement progressif de l'exploration proprement dite par le tourisme (Cogez, 2004,19).

Num mundo globalizado, com cada vez menos espaço para a viagem de exploração e com diferenças culturais mais diluídas, é legítimo perguntar qual o sentido da viagem. A relação entre exploração e viagem já não é óbvia, se comparada com outras épocas, e a figura do viajante surge investida das funções de observador, mais do que das de explorador. Primeiro, o turismo, depois, os meios de divulgação de massa modificaram, substancialmente, a relação do homem com o mundo. A própria relação dos indivíduos com o tempo implicou novas práticas. Na sua vocação de representar espaços, a literatura de viagens configura o mapa das deslocações geográficas. Neste sentido, viajar também é mapear um território. No entanto, uma vez mais, a literatura de viagens tem de conviver com a contradição, uma vez que textualizar é tornar fixo o que, na origem, é movimento.

O pacto que o narrador de viagens estabelece com o seu leitor virtual assenta, fundamentalmente, na referencialidade e na verdade dos fatos relatados: “Tout récit de voyage se caractérise par le pacte référentiel que d'emblée le narrateur scelle avec son lecteur. Implicite mais consubstanciel au genre, ce pacte pourrait de façon simple s'énoncer de la façon suivante: "Je vais vous raconter ce que j'ai vu" (Cogez, 2004, 22). O ato comunicativo inerente ao processo de escrita encontra mecanismos que parecem responder à necessidade de interpelar o leitor e, certamente, de o fazer viajar no texto: o esforço de encontrar pontos de contato 
entre duas realidades, num vaivém constante entre cultura de partida e cultura de chegada. Por intermédio deste tipo de relatos, o leitor viaja por procuração. Não obstante, o olhar do viajante está condicionado antes mesmo da viagem: pela sua bagagem cultural, pelo seu quadro de referências, pelas suas leituras, por determinados tópicos que fazem parte da escrita do gênero. Os textos de viagem, por apontarem para um espaço e tempo específicos, selecionam, talvez mais do que qualquer outro gênero, o seu leitorado, em função da enciclopédia comum partilhada por autor e leitor.

Com efeito, a literatura de viagens tem uma natureza compósita e comunica com outros gêneros, o que faz dela um gênero híbrido: "La primera consideración que debe hacerse es que la literatura de viajes es un género mudable, que se solapa con otros géneros, con los que comparte una frontera en continuo movimiento" (Nucera, 2002, 242). Esta característica decorre da circunstância de ter resgatado textos que, originalmente, tinham outras finalidades, como é o caso de textos oficiais, os quais eram uma espécie de impressões de contato, de carácter informativo e impressionista ${ }^{5}$, com os povos, culturas e paisagens encontradas nas expedições marítimas da expansão ultramarina. A releitura destes textos a uma nova luz, a da viagem como forma específica de organização e composição textual, confere-lhes um estatuto diferente. Ora, tal redimensionamento na maneira de considerá-los implica uma mudança de estatuto literário: "es el lector el que hace aflorar los aspectos creativos y narrativos que no fueron la primera preocupación del escritor” (Nucera, 2002, 243). Ademais, estes textos possuem um importante valor documental - historiográfico, etnográfico e

5 Diz ainda Todorov, na mesma publicação: “S'agissant de récits de voyage, le terme le plus approprié pour désigner les récits non allégoriques serait peut-être celui d'impressioniste, car il est historiquement attesté, et qu'il suggère bien que le voyageur se contente de nous faire part de ses impressions, sans chercher à nous enseigner autre chose" (Todorov, I99I, I03). 
Apontamentos teóricos sobre Literatura de Viagens

Paula Cristina Ribeiro da Rocha de Morais Cunha

antropológico - e imagológico, pois possibilitam não só a apreensão da sensibilidade, do imaginário e da mundividência dos povos europeus da época, como também constituem fonte importante de informação histórica. Não é, pois, de estranhar que, num período da história da humanidade em que os conhecimentos empíricos proporcionados pelas viagens permitiram enormes avanços técnicos e científicos, novas ciências, como a Etnografia e a Antropologia, tenham se estabelecido, tendo sido os relatos dessas viagens transmissores e difusores de informação relevante para a constituição de novos domínios de saber.

A natureza permeável e fronteiriça do gênero viático aproxima-o de uma literatura pessoal, intimista, de natureza essencialmente autobiográfica. É evidente que os fatos em estado bruto não são transpostos para o relato, mas é legítimo que a lógica de composição destes textos procure traduzir certa espontaneidade, mesmo tratando-se de exercícios fortemente marcados pela subjetividade do narrador-viajante, que recorre ao travelogue como auxiliar de memória, o que, por si só, problematizaria a pretensão de conformidade estrita com o real. Porém, em última análise, um dos atrativos de textos desta natureza (pelo menos, dos mais atuais) é, justamente, a relativização dos pontos de vista em relação à realidade por parte dos narradores-viajantes. Os textos dão-se à leitura como resultado de uma viagem específica, como contingenciais, com notações diarísticas que servem para ancorá-los num hic et nunc. Se os ensinamentos que veiculam permitem ultrapassar os elementos contingenciais, é porque o espírito humano transcende as balizas espaciais e temporais e concebe a própria vida como viagem, como percurso de vida de que o homem é agente, mas que também age nele e o transforma. Autores-viajantes como Nicolas Bouvier fizeram da viagem uma arte: "On croit qu'on va faire un voyage, mais bientôt c'est le voyage qui vous fait ou vous défait” (Bouvier, I992, I2).

170 
Em Los libros de viaje: realidad vivida y género literario, as questões sobre a conformidade com o real ou o caráter ficcional dos relatos de viagem são discutidas por diversos autores, que sublinham o fato de se tratar de um gênero literário que problematiza essas relações. No prólogo à coletânea, Leonardo Romero Tobar enuncia essa interpenetração como nevrálgica para a conceituação genológica:

Así pues, la interrelación entre experiencia vivida y escritura literaria es el hilo conductor de las distintas aproximaciones a viajeros concretos (Alí Bey, George Borro, Juana Valera, Julio Gamba), a los problemas históricos que suscitan los viajeros ilustrados y románticos, a las necesidades informativas que gravitan sobre el turista actual y, last but not least, a la definición teórica de un posible modelo del "relato de viaje" a partir de lo cual puede ser hacedero un recorrido intelectual de hondo calado (Tobar, 2005, 9)

Se os conceitos "fictional" e "conforming to reality" não são adequados para caracterizar a literatura de viagens, dadas as dificuldades em sustentar uma divisão de águas tão categórica, deve-se, então, considerá-la uma forma híbrida, "a frictional literature": "Between the pols of fiction and diction, the travelogue rather leads to a friction insofar as clear borderlines are also to be avoided as attempts to produce stable amalgams and mixed forms" (Ette, 2003, 3I).

Atendendo à pretensão de comunicar com outras culturas que as narrativas de viagem partilham com os guias turísticos, Nucera considera que "la literatura de viajes es una literatura internacional", pois "no sólo narra lugares extranjeros sino, para algunos aspectos, aspira también a la internacionalidad" $(2002,244)$. Pode-se, então, traçar a evolução da literatura de viagens a partir de categorias analíticas como o leitor, a existência de um mercado editorial que absorve este tipo de produção, o sistema de representação e de referência do autor-viajante 
Apontamentos teóricos sobre Literatura de Viagens

Paula Cristina Ribeiro da Rocha de Morais Cunha

que informa o seu discurso e o circuito de difusão e publicação internacional dos relatos:

Four general observations on European travel writing since the Enlightenment can be made: (I) an imagined reader always accompanies the travellers and is part of their perception as well as of their writing; (2) a strong book market grew in Europe during Enlightenment and economic profit became part of the cultural practice of travel as it had to not only be written for a home audience, but it also had to be sold to it. (3) all travel writers insert themselves into a discourse, they are part of a network transporting internationally shared knowledge systems attached to signs in all parts of the known and unknown world, as well as to sight, sound, and smell. (4) an often underestimated characteristic is the existence of an international network of writers and publishers since early modern times that was interconnected on a European level as well as reaching beyond Europe, especially to America and to the Mediterranean region. Travel writing is an international genre (Schulz-Forberg, 2005, 30).

Se, como se viu, a temática da viagem permite agrupar obras tão díspares na concepção, ela não é, no entanto, suficiente para incorporar todos os textos que versam a deslocação real ou imaginária. Há, pois, que considerar em que medida respondem à poética do género, que traços estruturais autorizam que a comunidade leitora os receba como textos "hodopóricos"6 (Nucera, 2002).

6 Segundo Nucera, o lexema "hodopórica", proposto pelo italianista Luigi Monga para designar a literatura de viagens, existe já no grego e significa "relacionado com a viagem" que deriva, por sua vez, de outro lexema grego com o sentido de caminho, viagem. O estudioso italiano acrescenta que "odeporico" consta dos dicionários italianos com o sentido de "relacionado com a viagem" e "relato de viagem". Na sua opinião, "hodopórico (a)", podendo ser usado como adjectivo - "un texto hodopórico" - ou como substantivo - "a hodopórica" -, "permitiría evitar los peligros de una definición como "literatura de viajes", que crea dificultades insuperables a la hora de emplearla como adjetivo" $(2002,247)$. 
CARACOL 3 / DOSSIÊ

\section{REFERÊNCIAS BIBLIOGRÁFICAS:}

Antoine, Philippe. Les récits de voyage de Chateaubriand: contribution à létude d'un genre. Paris: Editions Champion, I997.

Barthes, Roland. A aventura semiológica. Lisboa: Edições 70, I987.

Bouvier, Nicolas. L'usage du monde. Paris : Payot, 1992.

Buzard, James M. "What isn't travel?”. In:__. Unravelling civilisation: european travel and travel writing. Germany, P. I. E.: Peter Lang S.A., 2005, 55-60.

Cogez, Gérard. Les écrivains voyageurs au xxe siècle. Paris : Point Essais, Éditions du Seuil, 2004 .

Conrad, Joseph. Jeunesse. Gallimard, I993.

Cristóvão, Fernando. Condicionantes culturais da literatura de viagens. Coimbra: Almedina, 2002.

Ette, Ottmar. Literature on the move. New York-Amsterdam: Rodopi, 2003.

Gannier, Odile. La littérature de voyage. Paris : Ed.Ellipses, $200 \mathrm{I}$.

Nucera, Domenico. "Los viajes y la literatura”. In: Gnisci, Armando (org.). Introducción a la Literatura Comparada, Barcelona: Editorial Crítica , 2002, 24I$243,247$.

Pageaux, Daniel-Henri. "Da imagética cultural ao imaginário". In: Brunel, Pierre; Chevrel, Yves (orgs). Compêndio de literatura comparada. Lisboa: Fundação Calouste Gulbenkian, 2004. 
Apontamentos teóricos sobre Literatura de Viagens

Paula Cristina Ribeiro da Rocha de Morais Cunha

Richard, Jean. Les récits de voyages et de pèlerinages. Brepols: Institut d'Études Médiévales, I98I.

Schulz-Forberg, Hagen. Unravelling civilisation: european travel and travel writing. Germany, P. I. E.: Peter Lang S.A., 2005.

Tobar, Leonardo Romero; Elduayen, Patricia Almarcegui (orgs.). "La reescritura en los libros de viaje: las cartas de Rusia de Juan Valera”. In: __ . Los libros de viaje: realidad vivida y género literario. Universidad Internacional de Andalucía: Ediciones Akal, 2005. p. 9-IO, I32.

Todorov, Tzvetan. Les morales de l'histoire. Paris : Éditions de Philosophie, I99I. 